\title{
An unintended experiment in fisheries science: a marine area protected by war results in Mexican waves in fish numbers-at-age
}

\author{
Doug Beare • Franz Hölker • Georg H. Engelhard • \\ Eddie McKenzie • David G. Reid
}

Received: 4 December 2009 /Revised: 11 June 2010 / Accepted: 22 June 2010 /Published online: 13 July 2010

(C) The Author(s) 2010. This article is published with open access at Springerlink.com

\begin{abstract}
Marine protected areas (MPAs) are attaining increasing importance in the management of marine ecosystems. They are effective for conservation in tropical and subtropical areas (mainly coral and rocky reefs), but it is debated whether they are useful in the management of migratory fish stocks in open temperate regions. World War II created a large marine area within which commercial
\end{abstract}

Electronic supplementary material The online version of this article (doi:10.1007/s00114-010-0696-5) contains supplementary material, which is available to authorized users.

\section{Beare $\cdot$ F. Hölker}

European Commission, DG Joint Research Centre,

Institute for the Protection and Security of the Citizen,

Maritime Affairs,

Ispra, Italy

\section{Beare $(\square)$}

Wageningen-IMARES,

Haringkade 1, Postbus 68, Ijmuiden 1970 AB, The Netherlands

e-mail: doug.beare@gmail.com

\section{F. Hölker}

Leibniz-Institute of Freshwater Ecology and Inland Fisheries,

Berlin, Germany

G. H. Engelhard

Centre for Environment,

Fisheries and Aquaculture Science (Cefas),

Lowestoft, UK

\section{E. McKenzie}

Department of Statistics and Modelling Science,

University of Strathclyde,

Glasgow, Scotland, UK

D. G. Reid

Marine Institute,

Rinville,

Oranmore, Co. Galway, Ireland fishing was prevented for 6 years. Here we analyse scientific trawl data for three important North Sea gadoids, collected between 1928 and 1958. Using statistical models to summarise the data, we demonstrate the potential of MPAs for expediting the recovery of over-exploited fisheries in open temperate regions. Our age-structured data and population models suggest that wild fish stocks will respond rapidly and positively to reductions in harvesting rates and that the numbers of older fish in a population will react before, and in much greater proportion, than their younger counterparts in a kind of Mexican wave. Our analyses demonstrate both the overall increase in survival due to the lack of harvesting in the War and the form of the age-dependent wave in numbers. We conclude that large closed areas can be very useful in the conservation of migratory species from temperate areas and that older fish benefit fastest and in greater proportion. Importantly, any rise in spawning stock biomass may also not immediately result in better recruitment, which can respond more slowly and hence take longer to contribute to higher future harvestable biomass levels.

Keywords Marine protected areas · North Sea . World War II · Age-structured population · Gadoids . Exploitation $\cdot$ Mortality

\section{Introduction}

In 1939, the North Sea was almost entirely closed to commercial fishing until 1945 due to the outbreak of World War II (WWII). Fishing vessel movements were severely restricted because of the dangers of mines, surface and submarine naval activity and potential aerial attacks, and many fishing vessels were sunk in the hostilities. Fishermen were 
called up, especially those at prime age, and most fishing vessels, including the most modern trawlers, were requisitioned for war service; in particular for deployment as mine sweepers (Beverton and Holt 1957; Gulland 1968; Hannesson 2007; Engelhard 2008). Thus, fishing effort in the North Sea was very significantly reduced; for example, effort by British steam trawlers, the dominant fishing fleet at the time, fell by 97\% between 1938 and 1941 (Note: there were 2 million hours fishing in 1938, see Engelhard 2005). The War thus created, at $575,000 \mathrm{~km}^{2}$, an extensive, 'accidental' marine protected area (MPA) or arguably a 6-year temporary closure to fisheries. In comparison, the world's largest network of notake marine reserves on Australia's Great Barrier Reef covers a mere $115,000 \mathrm{~km}^{2}$ (Russ et al. 2008).

The effects of WWII on fish population dynamics have hardly been researched in recent years, in spite of the availability of data and their potential utility for addressing key problems in fisheries management. Although warmediated effects on plaice Pleuronectes platessa populations in the southern North Sea have been examined (Graham 1949; Wimpenny 1953; Beverton and Holt 1957), only a few authors have explored such effects on the commercially important gadoid species in the northern North Sea, and no detailed information exists on changes in age structure that occurred when fishing mortality ceased (Margetts and Holt 1948; Parrish 1948). Studies on the effects of WWII may, however, help to place in context the substantial population fluctuations that North Sea gadoids showed in the immediate post-war decades, including the 'Gadoid Outburst' of the 1960s-1980s (a period of especially favourable recruitment and high landings of haddock Melanogrammus aeglefinus, cod Gadus morhua and whiting Merlangius merlangus) and the sharp population declines of these species thereafter (Hislop 1996; Bannister 2004).

MPAs have also become a major focus in fisheries management and marine ecology (Halpern and Warner 2003; Russ et al. 2008; White et al. 2008). The European Union is a signatory of the Johannesburg Declaration on sustainable development which calls for a network of MPAs to be established by 2012 (United Nations 2002). Of those MPAs that have been scientifically monitored and shown to be effective, most are in the (sub-) tropics (mainly coral and rocky reefs) or in kelp forests: i.e. they are almost exclusively inshore. One reason often cited for the success of MPAs in lower latitudes is that their fish populations tend to live out their lives in more clearly defined habitats. In open, temperate marine regions where dispersal potential and gene flow in fish are higher, there remains much debate over whether MPAs will be effective measures for conservation at all (Hilborn et al. 2004; Worm et al. 2006; Blyth-Skyrme et al. 2006; Laurel and Bradbury 2006; Hölker et al. 2007), and it has been suggested that gadoid stocks typically fail to recover after population declines and moratoria on fishing activities (Hutchings 2000). There is, however, little quantitative information on how fish populations in temperate seas actually respond to the implementation of MPAs. The aim of this paper is to reveal, quantitatively, the response of three fish populations to a temporary (6-year) cessation in harvesting using fishery independent data. This is done with a simple statistical summary of trawl survey data analysed in the context of the available commercial data, a population model and relevant environmental data.

Total instantaneous mortality $(Z)$ on a fish population is the sum of fishing $(F)$ and natural $(M)$ mortality (Beverton and Holt 1957). Thus, the war-mediated MPA 'experiment' allows us to examine changes from an $F+M$ state to an $M$ state and back again to an $F+M$ state. First principles suggest that a reduction in $F$ : (a) cannot cause an immediate increase in recruitment, i.e. there may have to be a lag before increases in the numbers of sexually mature adults can feed forward into increased numbers of recruits (see theoretical age-structured population model described in S1); (b) will lead to an increase in the numbers of older fish in the population; and (c) will result in an age-dependent wave, the timing and magnitude of the response by each age-class following each other successively in a cascade. This phenomenon is comparable to 'Mexican waves', which surge through rows of spectators at a football stadium (Farkas et al. 2002). These expectations were supported by the actual data available.

\section{Material and methods}

Scientific trawl survey data in the form of lengthfrequencies and age-length keys were made available by Marine Science Scotland, Aberdeen for the entire northern North Sea, spanning the period between March 1925 and December 2007. After detailed examination of the data, we opted to consider only area 'Buchan' (Fig. 1) for the period between 1928 and 1958. Buchan was selected because there was consistent spatial coverage over time. The period 1928 to 1958 was chosen because it spanned the war and because the research vessels and gears used to collect the data were consistent. The area is possibly also sufficiently small to be comparable to a realistic marine protected area in future. Numbers-at-age matrices for cod, haddock and whiting were constructed from survey age-length keys and lengthfrequencies (see S2, S3, and S4 for data). These data were log-transformed and changes in age structures over time summarised using the following series of regression models:

1. $\ln ($ cpue $)=1$

2. $\ln ($ cpue $)=$ year 


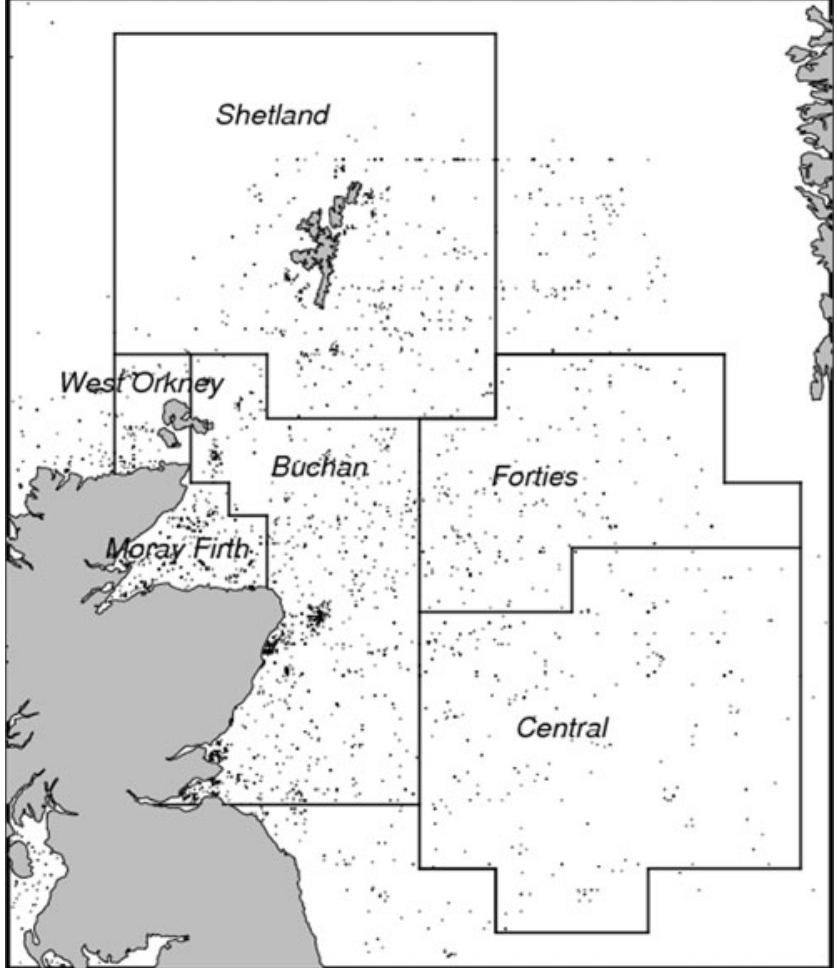

Fig. 1 Map of the study area Buchan. Dots denote trawl haul locations (shooting) 1928-1958

3. $\ln ($ cpue $)=$ year + age

4. $\ln ($ cpue $)=\operatorname{smooth}($ year $)+$ age

5. $\ln ($ cpue $)=\operatorname{smooth}($ year $) \times$ age

Analyses of variance tests between these successively more complex, nested models enabled us to find the 'best' model. Model 1 is the NULL model; 2 assumes that $\ln$ (cpue) depends linearly on age; and 3 that $\ln$ (cpue) depends linearly on both year and age. In model $4, \ln$ (cpue) is also linearly dependent on age, but its dependence on year is flexible and estimated using a smooth (locally weighted regression) function. In all cases, however, model 5 was chosen as both the most appropriate since it allows the abundance of each age group to change both non-linearly (smoothly) and independently with year. That is to say significant interactions between year and age mean that the shapes or trends of the modelled lines can be different for each age group.

Commercial data were obtained (or extracted) from hand-drawn maps and charts supplied by Cefas, Lowestoft, England (Engelhard 2005). Total landings, total numbers of hours fished by the commercial steam trawler fleet and hence catch per unit effort were made available by year and ICES statistical rectangle.

\section{Results}

\section{Stock dynamics}

In haddock, the abundance of all age groups fell steadily in the population between 1928 and 1939. The gradients of this decline, however, get flatter as age increases (Fig. 2). Between 1939 and 1945, all age groups, except the age 0s (recruits), experienced a step-wise increase in abundance. In the younger fish (ages 2 and 3), this increase continued until the end of the series in 1958. Abundances of older fish (e.g. ages 4 to 8) dipped between 1947 and 1950, after they
Fig. 2 Haddock trawl survey index (ages 0, 2-8) in area Buchan for August-October (1928-1958). The thin broken lines represent the raw data, the thicker lines the fitted models. The two vertical solid lines delineate WWII

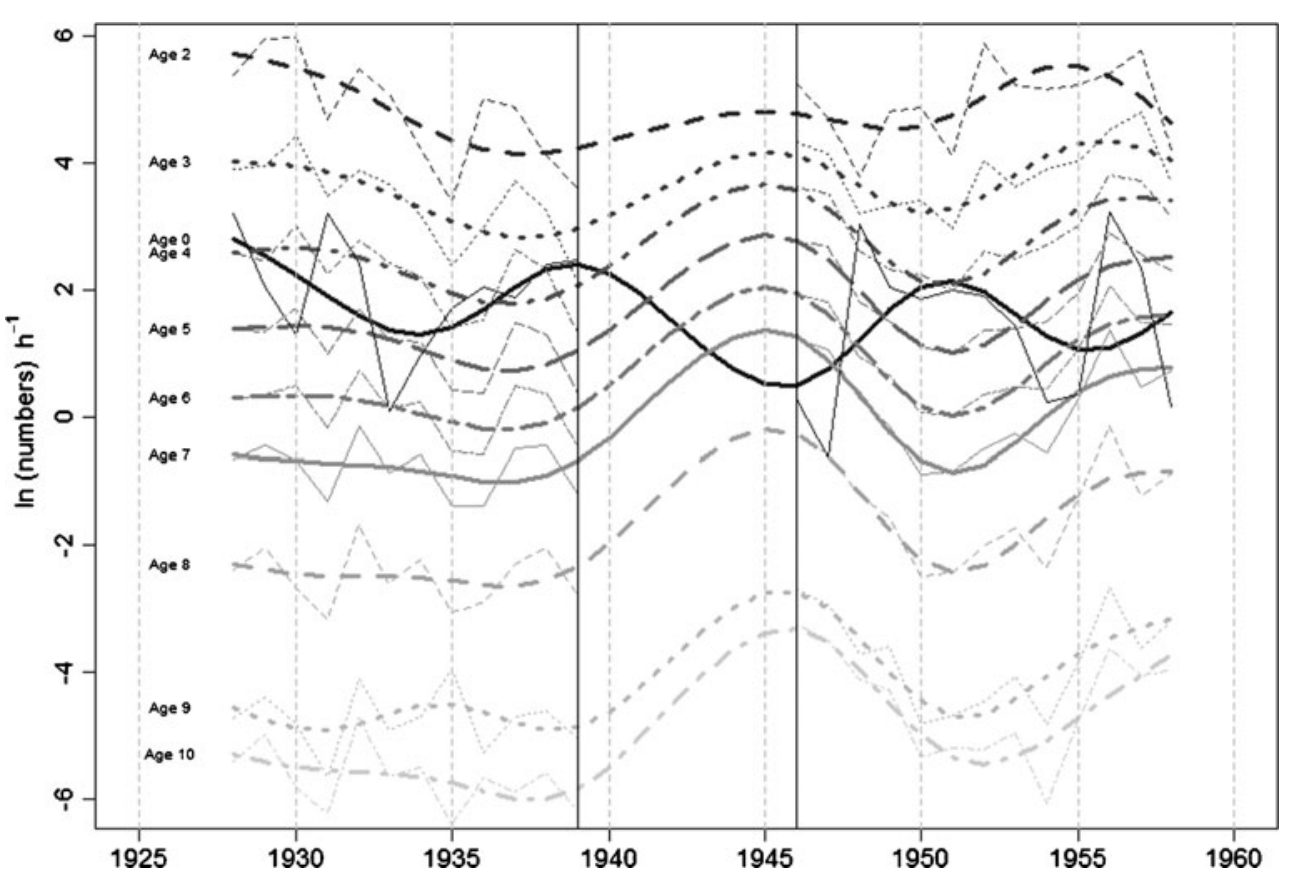


again began to increase. It is interesting to note the similarities in time trend between the trawl survey numbers per unit effort (Fig. 2) and the commercial landings per unit effort (Fig. 3) data where the older fish from the trawl survey mirror the U-shaped pattern seen in the commercial data. In cod (see S5), there was a peak in abundance in 1935 followed by a dip into the war period and a strong recovery between 1939 and 1945. After the war when fishing recommenced, abundances fell just like haddock with the trough occurring in the early 1950s. Unlike haddock, recruitment (age 0s) in cod also increased during the war, although this appears to have been part of an overall longterm decline (1928-1958). The commercial data for cod show rising landings per unit effort between 1928 and 1938, an abrupt increase in 1947, followed by a fall and then recovery (see Fig. 3). The trawl survey data for whiting (see S6) have parallel time trends for ages 3-9: there is a peak in the early 1930s followed by abrupt increases between 1939 and 1945. After the war, increased fishing effort again caused a fall, followed by rising abundance into the late 1950s. Recruitment in whiting (age 0s) also appeared to 'dip' into the early part of the war period and increased thereafter. The commercial data (see Fig. 3) suggest overall rising abundance between 1928 and 1958 .

Consider the cohort trajectories (1928 to 1958) from the modelled indices from Buchan for the three gadoids
Fig. 3 Total annual haddock, cod and whiting commercial landings (a), effort (b), and landings per unit effort (c) for the steam trawler fleet in Buchan in 1928 to 1958
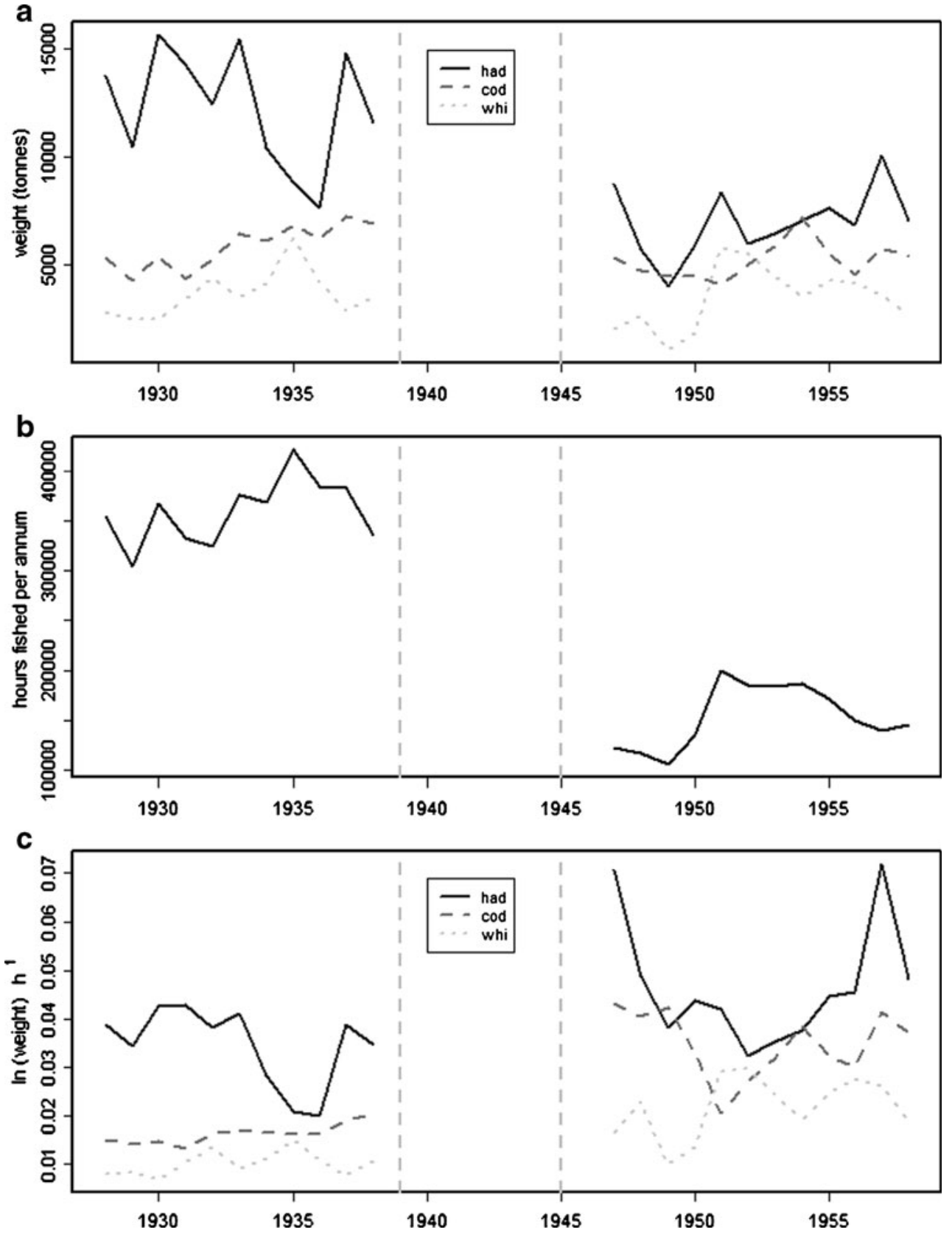
plotted in Fig. 4a-c. The change in gradients between the pre, post and WWII periods has been extracted from linear models fitted to each cohort and plotted in Fig. 5. The gradients of these lines represent a measure of total mortality ( $Z$ ). A component of $Z$ is due to mortality by fishing $(F)$, and another unknown component is due to mortality by predation and disease (natural mortality, $M$ ). Estimates of $Z$ (see Fig. 5) peaked for all species during the period immediately before WWII, mirroring the change in fishing effort (see Fig. 3). The effect of the cessation of fishing during WWII was dramatic, with sharp increases in the rate of decline in total mortality $(Z)$ being observed in all three of the gadoids examined.
Lowest mortalities were observed in 1942 (haddock), 1944 (cod) and 1945 (whiting), after $Z$ began to rise again as fishing recommenced in the post-war period. Mortality rates never again reached the high levels observed in the late 1920 s and 1930 s, presumably since similar levels of effort $(300,000 \mathrm{~h})$ were not attained in the aftermath of WWII because much of the fleet capacity and its manpower had been negatively affected by the general war effort. In Fig. 6, the indices for haddock have been rescaled for each age category so that all previous and subsequent observations in each time series reflect change relative to 1939 , i.e. to the start of hostilities and to the cessation of commercial fishing.
Fig. 4 a Haddock cohorts (ages 2 to 8 ) in area Buchan estimated from scientific trawl survey data. b Cod cohorts (ages 2 to 5) in area Buchan estimated from scientific trawl survey data. c Whiting cohorts (ages 3 to 9) in area Buchan estimated from scientific trawl survey data
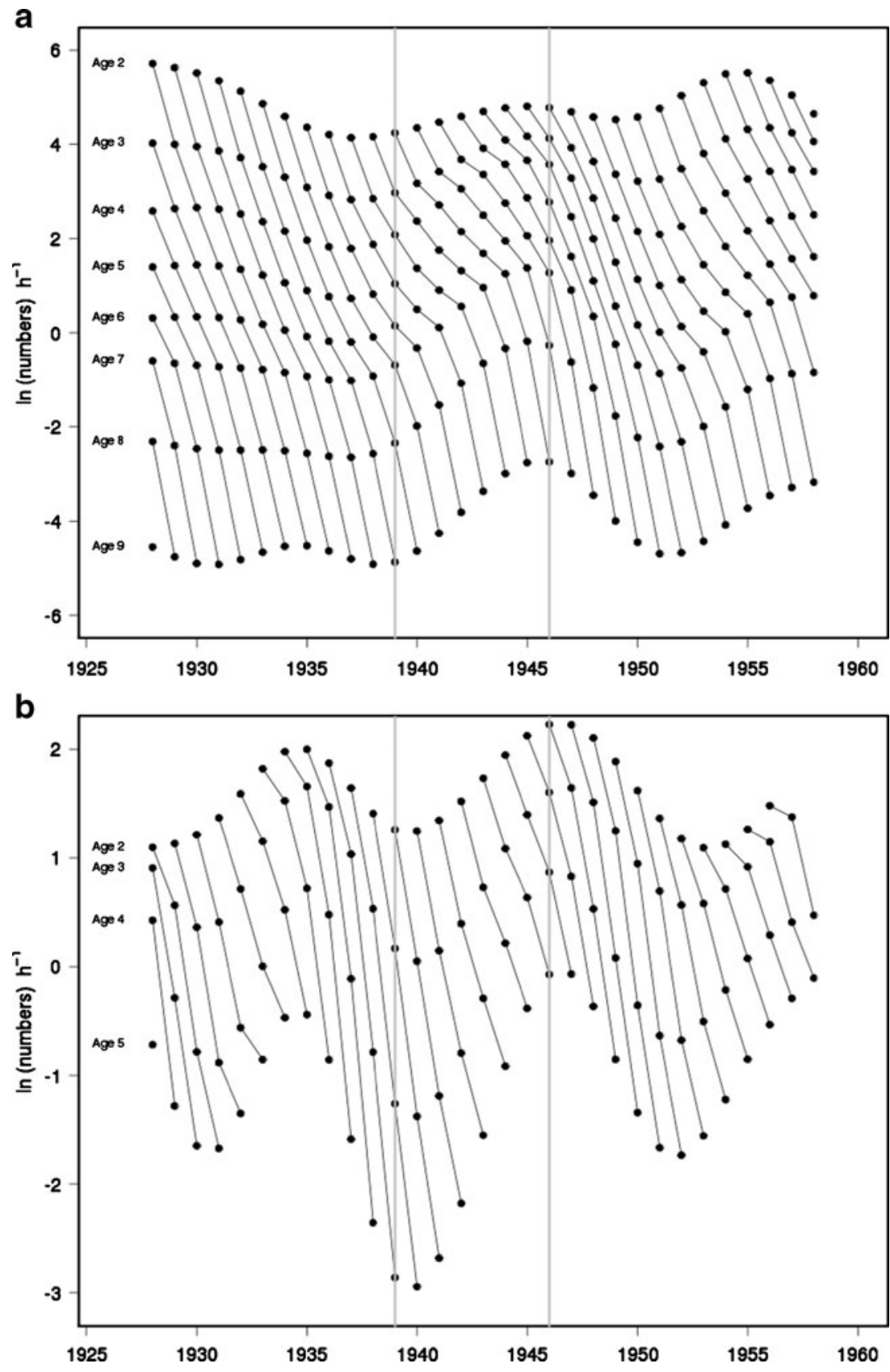
Fig. 4 (continued)

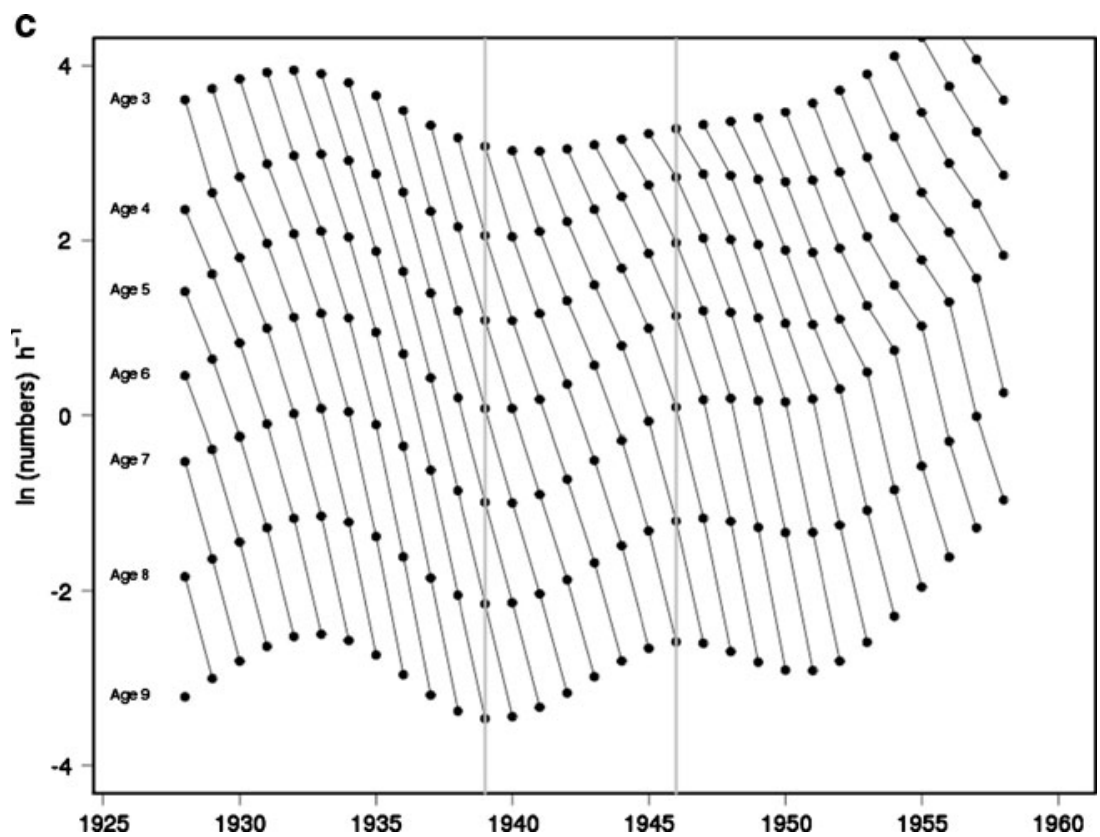

The Mexican wave in the haddock population suggested by first principles is clear. The youngest fish (age 0s) responded negatively, levels falling by $83 \%$ between 1939 and 1945, whereas the older age categories all responded positively. The mean level of age 10 haddock in the population rocketed, increasing nearly 12 times between 1939 and 1945. Increases by the younger age groups were found to be arranged in an ordered sequence between these two extremes; for example, age 8 s increased by $747 \%$, age 6s by $579 \%$, age 4 s by $427 \%$ and age 2 s by $170 \%$. It should be noted that this wave is seen twice but travelled in the reverse direction after 1945 when levels of older fish decreased further and fastest when fishing recommenced in the post-war period (Fig. 6). A similar phenomenon was observed in both cod, G. morhua, and whiting, $M$. merlangus, although the numbers of younger fish in the population also rose in those species.

Both mean length and mean biomass have been suggested as useful indicators for assessing conservation and fisheries-related effects of MPAs (Pelletier et al. 2008), and this study supports that view. The mean length of haddock in the trawl survey sampled Buchan population was $24.8 \mathrm{~cm}$ in 1939 and $28.7 \mathrm{~cm}$ in 1945 , while the catch per unit effort (in weight) of haddock rose from 11 to $59 \mathrm{~kg}$ $\mathrm{h}^{-1}$ of fishing. Similarly, cod average length in the trawl catches rose from $45.8 \mathrm{~cm}$ just before the war to $51.2 \mathrm{~cm}$ just after, while average whiting lengths increased from 26.5 to $27.8 \mathrm{~cm}$. The catch per unit effort of cod increased
Fig. 5 Total haddock, cod and whiting mortality $(Z)$ on ages 2-4 estimated from the trawl survey data $1928-1958$

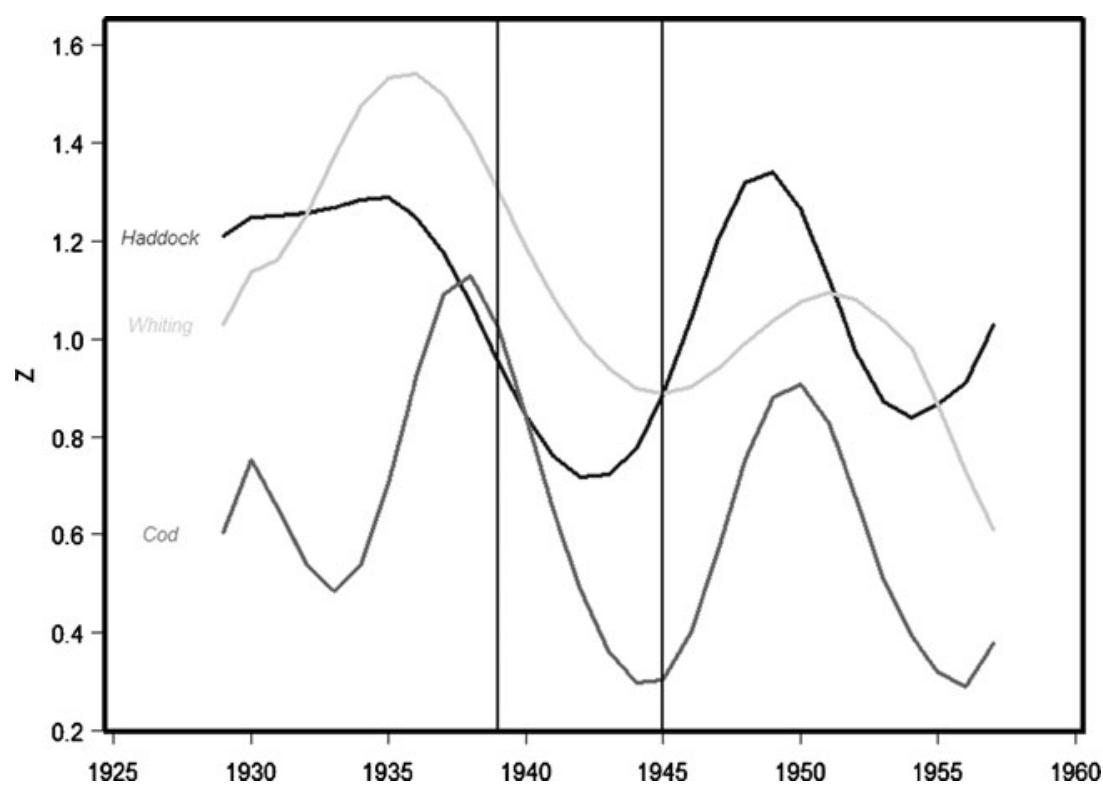


Fig. 6 The Mexican wave: haddock trawl survey abundance index for ages $0,1,2,4,6,8$ and 10 between 1928 and 1958 (Note: the series have been scaled to equal one in 1939)

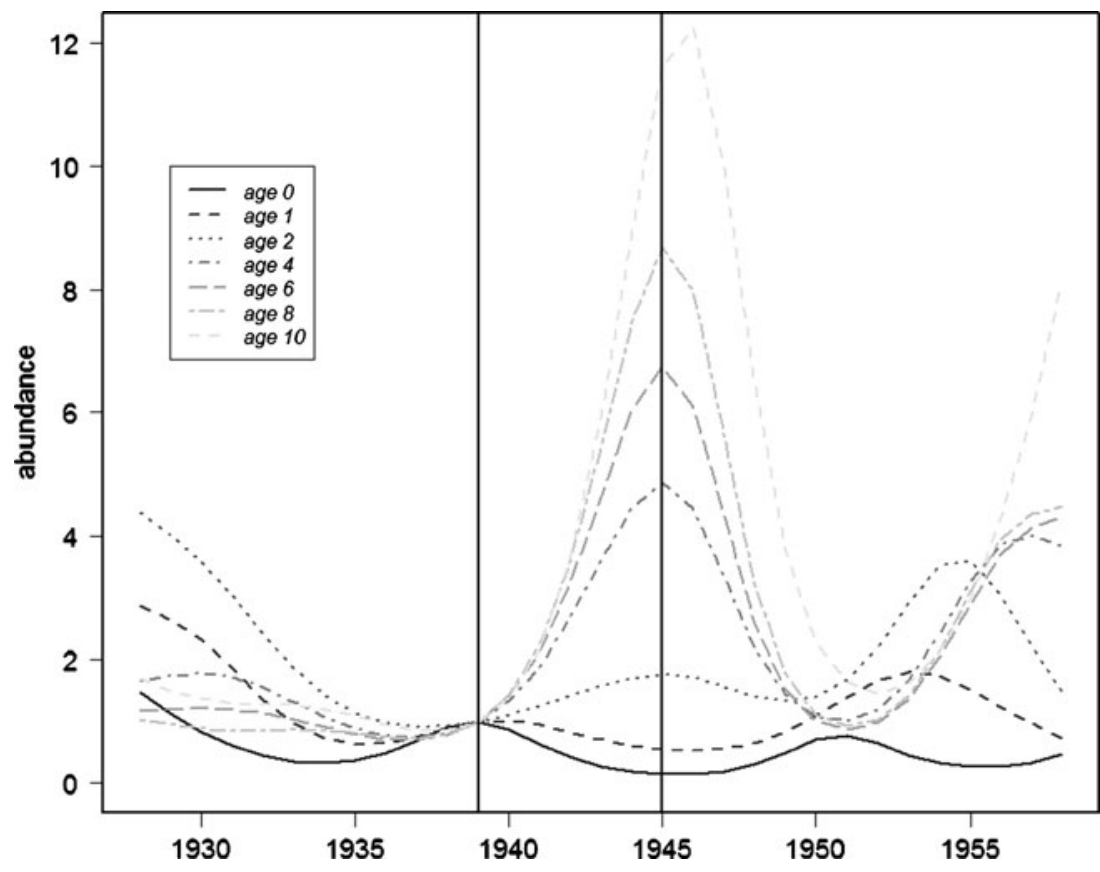

nearly ten times from $4 \mathrm{kgh}^{-1}$ in 1939 to $36 \mathrm{kgh}^{-1}$ in 1945 . Changes in whiting catch per unit effort were more modest, trebling from $5 \mathrm{kgh}^{-1}$ in 1939 to $16 \mathrm{kgh}^{-1}$ in 1945 . Substantial increases in the catch per unit effort were also seen in the commercial data.

\section{Environmental effects on stock dynamics}

We hypothesised that the changes observed in gadoid abundance in Buchan, between 1939 and 1945, might plausibly have been caused by environmental factors such as changes in temperature or the volume of Atlantic inflow rather than by fishing. Above, we examined how the entire age structure of each of the three most important gadoids changed, between 1928 and 1958, using population abundance indices from trawl surveys. To examine the possible impact of changes due to the physical environment as opposed to those due to commercial fishing, we opted to simplify the problem by examining only 'recruits' (age 0s) and spawing stock biomass (SSB) (all the fish thought to be old enough to reproduce estimated using maturity-at-length data), comparing them to a range of environmental covariate data we were able to assemble.

Tables 1, 2 and 3 show pair-wise correlations (19281958) between two indices (i.e. $R \_$age $0=$ numbers of age 0 fish which is also known as 'recruitment' and SSB = numbers of sexually mature fish) representing changes in the haddock, cod and whiting populations and some potentially explanatory oceanographic variables: temperature, salinity and the North Atlantic Oscillation Index [Note: some sea surface temperature data are available for the war time period]. The haddock recruits (Table 1) were positively correlated with SSB $(r=0.35)$ and negatively correlated with temperature in quarter $3(r=-0.43)$. There was also a negative relationship between haddock SSB and salinity in quarter $3(r=-0.36)$. Cod recruitment (Table 2$)$

Table 1 Haddock: correlation coefficients between recruits, spawning stock biomass (SSB) the year before, sea surface temperature (SST), salinity (SAL) and the North Atlantic Oscillation index (NAO)

\begin{tabular}{lrrrrrrrr}
\hline & $R \_$age & SSB & SSBt-1 & SST Q3 & SST Q1 & SAL Q3 & SAL Q1 & NAO \\
\hline$R$ & 1.00 & 0.35 & 0.10 & -0.43 & 0.03 & -0.02 & -0.18 & 0.02 \\
SSB & 0.35 & 1.00 & 0.61 & -0.01 & -0.10 & -0.36 & -0.17 \\
SST Q3 & -0.43 & -0.01 & 0.07 & 1.00 & -0.09 & 0.26 & 0.23 \\
SST Q1 & 0.03 & -0.10 & 0.01 & -0.09 & 1.00 & 0.44 & 0.37 \\
SAL Q3 & -0.02 & -0.36 & -0.12 & 0.26 & 0.44 & 1.00 & 0.18 \\
SAL Q1 & -0.18 & -0.17 & -0.12 & 0.23 & 0.57 & 0.35 & 0.48 \\
NAO & 0.02 & -0.30 & 0.11 & -0.18 & 0.48 & 0.24 & -0.06 \\
\hline
\end{tabular}

Q1 and Q3 denote that the data were calculated for quarter 1 (January, February, March) and quarter 3 (July, August, September) 
Table 2 Cod: correlation coefficients between recruits, spawning stock biomass (SSB) the year before, sea surface temperature (SST), salinity (SAL) and the North Atlantic Oscillation index (NAO)

\begin{tabular}{lcccccrrr}
\hline & $R \_$age0 & SSB & SSBt-1 & SST Q3 & SST Q1 & SAL Q3 & SAL Q1 & NAO \\
\hline$R$ & 1.00 & -0.06 & -0.06 & -0.04 & 0.04 & -0.41 & -0.21 & 0.01 \\
SSB & -0.06 & 1.00 & 0.7 & 0.18 & 0.2 & 0.03 & 0.26 & 0.23 \\
SST Q3 & -0.04 & 0.18 & 0.33 & 1.00 & -0.09 & -0.18 \\
SST Q1 & 0.04 & 0.2 & -0.13 & -0.09 & 1.00 & 0.44 & 0.57 & 0.48 \\
SAL Q3 & -0.41 & 0.03 & -0.14 & 0.26 & 0.44 & 0.00 & 0.35 \\
SAL Q1 & -0.21 & 0 & -0.34 & 0.23 & 0.57 & 0.35 & 1.00 \\
NAO & 0.01 & -0.06 & -0.14 & -0.18 & 0.48 & 0.24 & -0.06 \\
\hline
\end{tabular}

Q1 and Q3 denote that the data were calculated for quarter 1 (January, February, March) and quarter 3 (July, August, September)

was negatively correlated $(-0.41)$ with salinity in quarter 3 , whereas SSB was not related to any of the variables we examined. Recruitment in whiting, on the other hand, was negatively related to salinity in quarter $1(-0.46)$, while SSB was positively related to sea surface temperature in quarter 1 (Table 3). It should be noted here that there are also close connections between the oceanographic variables themselves: salinity and temperature being positively related.

These data have been plotted as time series in Fig. 7. Recruitment fell steadily between 1928 and 1939 in haddock, cod and whiting. In the case of haddock, recruitment fell further during the war and then rose again between 1945 and 1958. In both cod and whiting, recruitment rose during the war and in cod continued to rise thereafter (Fig. 7). Levels of recruitment in whiting, however, remained fairly stable after the war.

SSB in all three gadoids fell between 1928 and 1939. During the war, SSB levels of all three species rose. Immediately after WWII, spawner abundance dipped again, presumably when fishing recommenced, after spawner abundance rose again gradually.

In order to investigate these relationships in more detail, we extended the simple pair-wise correlation analysis (e.g. Tables 1, 2 and 3) by using a combination of multiple linear regression models on log-transformed data, together with traditional nonlinear stock-recruitment models (Ricker 1954). In both cod and whiting, spawning stock biomass was not clearly related to any of the environmental data: the best predictor being the SSB the year before (see Tables 2 and 3). In haddock, there is an indication $(r=-0.36$, Table 1$)$ that SSB might be negatively related to salinity during quarter 3 (SAL Q3). When this was tested with an analysis of variance (Table 4), however, it was not found to be statistically significant $(p=0.1)$.

An examination of environmental factors (e.g. temperature, North Atlantic Oscillation Index) thus failed to convincingly explain the abrupt changes in either the abundance of sexually mature fish or their changing age structure, and we are confident that they can be attributed to the virtual absence of fishing mortality.

\section{Stock-recruitment relationships}

It is usually assumed that recruitment $\left(R \_\right.$age 0$)$ is directly related either to SSB in year $t$ or to SSB the year before $\left(\mathrm{SSB}_{\mathrm{t}-1}\right)$. To explore these relationships, we fitted $R$ age 0 to the abundance of spawners, together with a range of environmental variables, using linear models and compared the output using nested analysis of variance tests. In

Table 3 Whiting: correlation coefficients between recruits, spawing stock biomass (SSB) the year before, sea surface temperature (SST), salinity (SAL) and the North Atlantic Oscillation index (NAO)

\begin{tabular}{lcrrrrrr}
\hline & $R \_$age0 & SSB & SSBt-1 & SST Q3 & SST Q1 & SAL Q3 & SAL Q1 \\
\hline$R$ & 1.00 & 0.12 & -0.03 & -0.19 & -0.1 & 0.08 & -0.46 \\
SSB & 0.12 & 1.00 & 0.56 & -0.23 & 0.33 & -0.03 & 0.27 \\
SST Q3 & -0.19 & -0.23 & 0.24 & 1.00 & -0.09 & 0.26 & -0.02 \\
SST Q1 & -0.1 & 0.33 & -0.07 & -0.09 & 1.00 & 0.44 & 0.23 \\
SAL Q3 & 0.08 & -0.03 & 0.16 & 0.26 & 0.44 & 1.00 & 0.57 \\
SAL Q1 & -0.46 & 0.27 & -0.24 & 0.23 & 0.57 & 0.35 & 0.35 \\
NAO & 0.07 & -0.02 & 0.33 & -0.18 & 0.48 & 0.24 & -0.00 \\
\hline
\end{tabular}

Q1 and Q3 denote that the data were calculated for quarter 1 (January, February, March) and quarter 3 (July, August, September) 

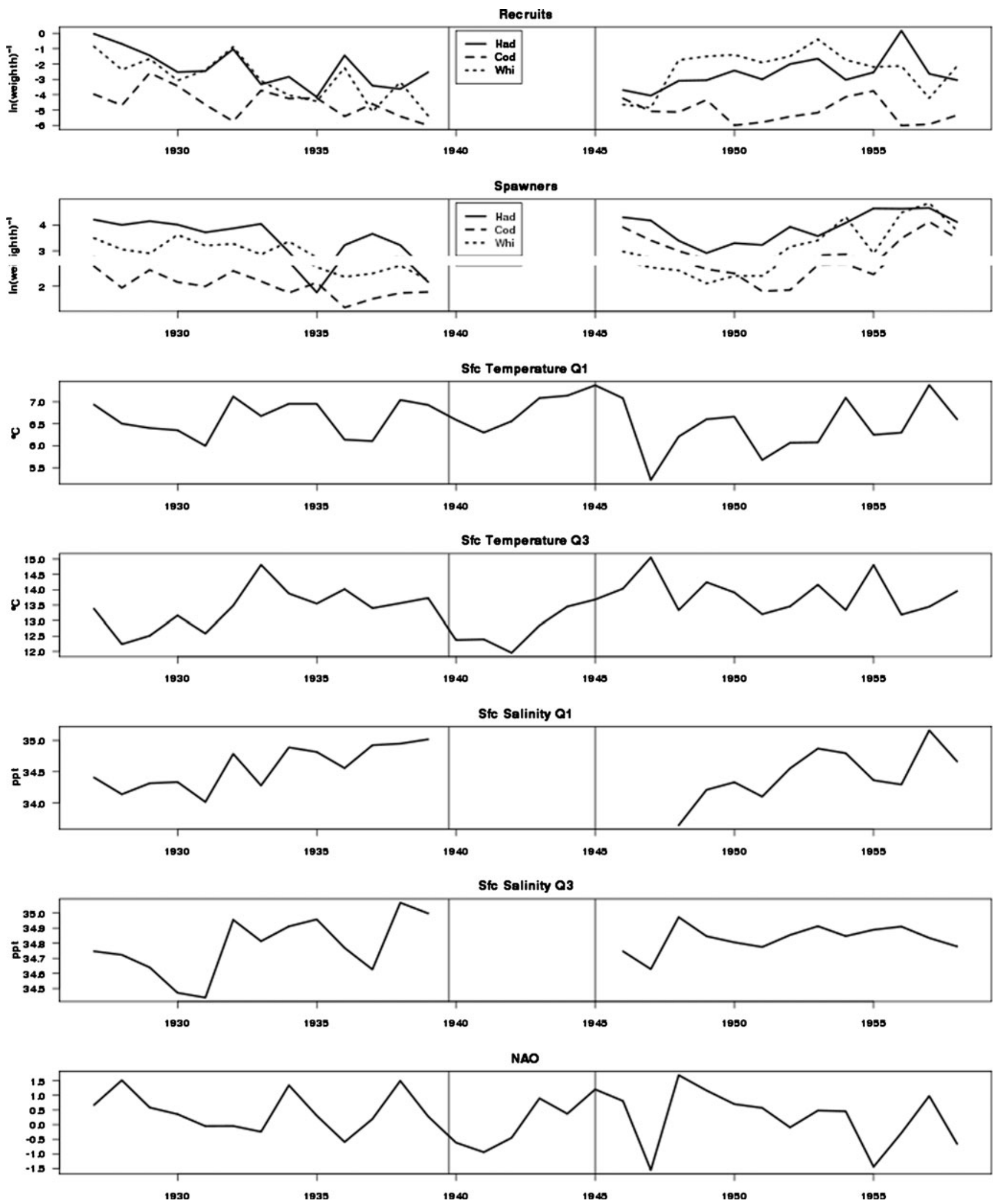

Fig. 7 Time series summarising change in the haddock, cod and whiting abundance together with five environmental variables in Buchan between 1928 and 1958 
Table 4 Haddock: analysis of variance summarising the relationship between spawners and salinity in Buchan during quarter 3

\begin{tabular}{lcccccc}
\hline Model & Res. $d f$ & RSS & $d f$ & Sum of Sq & $F$ & $\operatorname{Pr}(>F)$ \\
\hline 1. SSB $=1$ & 23 & 12 & & & & \\
2. SSB $=$ SAL Q3 & 22 & 10.6 & 1 & 1.4 & 2.9 & 0.1 \\
\hline
\end{tabular}

haddock, spawner abundance the year before $\left(\mathrm{SSB}_{\mathrm{t}-1}\right)$ was quickly eliminated, recruitment ( $R$ age 0$)$ being more strongly related to $\mathrm{SSB}$ in the same year. S7 shows that both SSB and temperature during quarter 3 (given that SSB is in the model) are related significantly to recruitment. The coefficients from model 3 are the following: intercept $=4.2$, $\mathrm{SSB}=0.5$ and $\mathrm{SST} \mathrm{Q} 3=-0.64$. Hence, rising late summer temperatures will result in falling recruitment. Between 1939 and 1945, average quarter 3 temperatures rose (see also Fig. 7), indicating that temperature could have caused the fall in recruitment that we see during the war. We also fitted a Ricker stock-recruitment curve to these data, adding quarter 3 temperature data as a covariate, according to the methods outlined in the FLR package (Kell et al. 2007). In this formulation, temperature in quarter 3 was not significant.

In the case of cod, neither SSB nor $\mathrm{SSB}_{\mathrm{t}-1}$ were useful for predicting cod recruitment in Buchan between 1928 and 1958 (see S8). Salinity in quarter 3 had a negative effect ( $p=0.06$ ) on cod recruitment, when SSB was also included in the model. Quarter 3 salinity fell between 1939 and 1946 (Fig. 7) and could, therefore, have been a factor in the increasing recruitment we observed during the war.

The patterns observed in haddock and cod were similar for whiting. Again, neither SSB nor SSB the year before could explain the pattern in whiting recruitment in Buchan between 1928 and 1958. Salinity in quarter 1 had a positive effect when SSB was also in the model (see S9), and so salinity in early spring might, therefore, have contributed to the increasing recruitment we observed during the war, since it fell quite sharply between 1938 and 1948 (Fig. 7), although the exact mechanism cannot be deduced from this study.

\section{Discussion}

We have 'tracked' the response of the entire age structure of three fish populations in a large temperate area through a complete closure to fishing, emphasising the important differential response by each age category. The first 'Mexican wave' we see, between 1939 and 1945, is caused by the enhanced survival rates due to the cessation of fishing, the effects of which accumulated steadily over time as each cohort aged. This result might at first appear obvious, but we have found no clear references to this effect (age-dependent cascade) in the literature. One reason might be that fishery science traditionally models the entire age structure but then aggregates the sexually mature component (the spawning stock biomass), and only its relationship to the 'recruits', i.e. the juvenile part of the stock (Pope and Macer 1996; Jennings 2001), is typically considered. This obscures independent changes that can take place in separate age classes. Further, the majority of population models for marine reserve designs currently include no detailed age structure for their resident populations (Gerber et al. 2003).

The fall in numbers of juvenile (age 0) haddock between 1939 and 1945 is interesting as it contrasts with increasing numbers of all older age classes. This appears to be due either to density-dependent effects or to the increase in late summer temperatures observed between 1939 and 1945, which may be directly or indirectly causative. Reduced mortality on older fish caused by zero harvesting raised levels of both inter- and intra-specific competition for resources, in addition to increasing mortality by both predation and cannibalism. In the case of haddock, this effect was not ameliorated by enhanced recruitment from a much larger spawning stock biomass possibly due to the lag effect clear from our population model (see S1) (Note: recruitment in both cod and whiting increased between 1939 and 1945, so the situation is extremely complex and a detailed discussion is beyond the scope of this article). Interestingly, there are also parallels with human populations in which changes in mortality rates, due, say, to better healthcare, lead to 'complete demographic transitions' from populations dominated by juveniles to those dominated by adults (Caldwell et al. 2006).

The reduction of mortality due to commercial fishing thus changed the entire structure of the gadoid populations in Buchan, reducing the relative numbers of younger fish and increasing the relative proportions of their older counterparts. Had fishing been prohibited for longer, it would have resulted in a completely new population 'equilibrium', bearing in mind that the 6-year duration of the war is far less than the longevity of all the gadoids examined, implying that none of the cohorts would have experienced an entire lifetime completely free from mortality due to fishing. This all has clear implications for the economics of the fishing industry, older fish generally being disproportionately more valuable. The maintenance of such populations would also reduce discarding of small nonmarketable fish which is a current objective of the Common Fisheries Policy of the European Union (Council of the European Union 2002). 
This work has the potential to enable 'managers' to quantify how the instigation of MPAs might affect fish stocks and to harvest them without damaging the resource. Predictions of the development of age structure in a population of migratory fish within a large open MPA can now be made. This has not been shown hitherto. In many cases, resource managers and stakeholders expect to see major benefits in the short term after the establishment of a marine protected area. Thus, an important question is the development of theoretical approaches that allow us to predict biologically reasonable time frames under which the effects of MPAs can be detected. We have shown how a reduction in fishing effort from 300,000 (the Buchan area) hours to practically zero over 6 years to around $100,000 \mathrm{~h}$ in the immediate post-war period impacted the age structure of gadoid populations in the northern North Sea. Such imputations would be impossible to make confidently using more contemporary data (e.g. most fish stock data used currently typically extend back to the 1960s), during which fishing levels have been consistent and ubiquitous.

In conclusion, this work shows that large closed areas can be useful in the conservation of migratory species from temperate areas, that older fish benefit fastest and that better recruitment may not occur instantly as it is more dependent on factors other than fishing and hence may take longer to feed through to higher biomass levels that can be harvested.

\begin{abstract}
Acknowledgements We would like to thank Marine Science Scotland in Aberdeen for providing the valuable datasets upon which this work is based and to the crews of the research vessels (Explorer I, Explorer II and Scotia I) who actually went to sea in all weathers to catch the fish. This study was carried out with financial support from the Commission of the European Communities, under the program "Specific Support to Policies", contract no. 022644 ("Capacity, F and Effort"). Work was also partially funded by the Exploratory Research Program of the Joint Research Centre. The original idea to re-examine the WWII effect come from a brief discussion Doug Beare had with Hendrik Doerner in the Joint Research Centre cafeteria after lunch one day. GHE was also supported by the European Union's FP6 project RECLAIM and the UK's Department for Environment, Food and Rural Affairs projects MA010 (Fisheries Supporting Studies) and M1108 (100 Years of Change). The funders had no role in study design, data collation and analysis, decision to publish or preparation of the manuscript.
\end{abstract}

Open Access This article is distributed under the terms of the Creative Commons Attribution Noncommercial License which permits any noncommercial use, distribution, and reproduction in any medium, provided the original author(s) and source are credited.

\section{References}

Bannister RCA (2004) The rise and fall of cod (Gadus morhua L.) in the North Sea. In: Payne AIL, O'Brien CM, Rogers SI (eds) Management of shared fish stocks. Blackwell Publishing, Oxford, pp 316-338
Beverton RJH, Holt SJ (1957) On the dynamics of exploited fish populations. Fish Invest, II 19:1-533

Blyth-Skyrme RE, Kaiser MJ, Hiddink JG, Edwards-Jones G, Hart PJB (2006) Conservation benefits of temperate marine protected areas: variation among fish species. Cons Biol 20:811-820

Caldwell JC, Caldwell BK, Caldwell P, McDonald PF, Schindlmayr T (2006) Demographic transition theory. Springer, Dordrecht, p 239

Council of the European Union (2002) Regulation (EC) No 2371/ 2002 of 20 December 2002 on the conservation and sustainable exploitation of fisheries resources under the common fisheries policy. Off J Eur Communities, L 358:59-80

Engelhard GH (2008) One hundred and twenty years of change in fishing power of English North Sea trawlers. In: Payne A, Cotter J, Potter T (eds) Advances in fisheries science 50 years on from Beverton and Holt. Blackwell Publishing, Oxford, pp 1-25

Engelhard GH (2005) Catalogue of Defra historical catch and effort charts: six decades of detailed spatial statistics for British fisheries. Sci Ser Tech Rep, Cefas Lowestoft 128:42

Farkas I, Helbing D, Vicsek T (2002) Mexican waves in an excitable medium. Nature 419:131-132

Gerber LR, Botsford LW, Hastings A, Possingham HP, Gaines SD, Palumbi S, Andelman S (2003) Population models for marine reserve design: a retrospective and prospective synthesis. Ecol Appl 13(Suppl):47-64

Graham M (1949) Overfishing. In: Proceedings of the United Nation's Scientific Conference on the Conservation and Utilisation of Resources (ed) VII. Wildlife and fish resources. FAO, Rome, pp $20-24$

Gulland JA (1968) Recent changes in the North Sea plaice fishery. J Cons Int Explor Mer 31:305-322

Halpern BS, Warner RR (2003) Matching marine reserve design to reserve objectives. Proc Roy Soc Lond B 270:1871-1878

Hannesson R (2007) Are fisheries going from bad to worse? The case of the Northeast Arctic cod. Int J Glob Environ Issues 7:137-157

Hilborn R, Stokes K, Maguire JJ, Smith T, Botsford LW, Mangel M, Oransanz J, Parma A, Rice J, Bell J (2004) When can marine reserves improve fisheries management? Ocean Coast Manage 47:197-205

Hislop JRG (1996) Changes in North Sea gadoid stocks. ICES J Mar Sci 53:1146-1156

Hölker F, Beare D, Dörner H, di Natale A, Rätz HJ, Temming A, Casey J (2007) Comment on "impacts of biodiversity loss on ocean ecosystem services". Science 316:1281

Hutchings JA (2000) Collapse and recovery of marine fishes. Nature 406:882-885

Jennings S (2001) Patterns and prediction of population recovery in marine reserves. Rev Fish Biol Fish 10:209-231

Kell LT, Mosqueira I, Grosjean P, Fromentin J-M, Garcia D, Hillary R, Jardim E, Mardle S, Pastoors MA, Poos JJ, Scott F, Scott RD (2007) FLR: an open-source framework for the evaluation and development of management strategies. ICES J Mar Sci 64:640 646. doi:10.1093/icesjms/fsm012

Laurel BJ, Bradbury IR (2006) Big concerns with high latitude marine protected areas (MPAs): trends in connectivity and MPA size. Can J Fish Aquat Sci 63:2603-2607

Margetts AR, Holt SJ (1948) The effect of the 1939-1945 war on the English North Sea trawl fisheries. Rapp P-V Réun-Cons Int Explor Mer 122:26-46

Parrish BB (1948) The haddock stocks in the North Sea during the second half of 1945. Rapp P-V Réun-Cons Int Explor Mer 122:47-54

Pelletier D, Claudet J, Ferraris J, Benedetti-Cecchi L, Garcia-Charton JA (2008) Models and indicators for assessing conservation and fisheries-related effects of marine protected areas. Can J Fish Aquat Sci 65:765-769

Pope JG, Macer CT (1996) An evaluation of the stock structure of North Sea cod, haddock, and whiting since 1920, together with a 
consideration of the impacts of fisheries and predation effects on their biomass and recruitment. ICES J Mar Sci 53:1157-1169

Ricker WE (1954) Stock and recruitment. J Fish Res Board Can 11:559-623

Russ GR, Cheal AJ, Dolman AM, Emslie MJ, Evans RD, Miller I, Sweatman H, Williamson DH (2008) Rapid increase in fish numbers follows creation of world's largest marine reserve network. Curr Biol 18:R514-R515

United Nations (2002) Johannesburg declaration on sustainable development (World Summit on Sustainable Development, Johannesburg)
White C, Kendall BE, Gaines S, Siegel DA, Costello C (2008) Marine reserve effects on fishery profit. Ecol Lett 11:370 379

Wimpenny RS (1953) The plaice (being the Buckland Lectures for 1949). Edward Arnold \& Co., London

Worm B, Barbier EB, Beaumont N, Duffy JE, Folke C, Halpern BS, Jackson JBC, Lotze HK, Micheli F, Palumbi SR, Sala E, Selkoe KA, Stachowicz JJ, Watson R (2006) Impacts of biodiversity loss on ocean ecosystem services. Science 314:787-790 